\title{
$\mathrm{RCP}$ 시나리오에 근거한 고해상도 미래 풍력 기상자원 분석
}

\author{
임윤정 1 김선애 ${ }^{1}$ 장동호 ${ }^{2} \cdot$ 박종철 $^{3}$ ·김연희 ${ }^{4} \cdot$ 김백조 $^{4} \cdot$ 김맹기 $^{1}$ \\ 1공주대학교 대기과학과 -2공주대학교 지리학과·3공주대학교 지리정보과학연구소 \\ 4국립기상과학원 응용기상연구과
}

(2015년 12월 10일 접수, 2016년 3월 28일 수정, 2016년 3월 30일 게재 확정)

\section{Analysis of the High-Resolution Future Wind Resource based on RCP Scenarios}

\author{
Yun-Jung $\mathrm{Lim}^{1} \cdot$ Seonae $\mathrm{Kim}^{1}$ · Dong-Ho Jang ${ }^{2}$ Jongchul Park ${ }^{3}$ Y Yeon-Hee Kim . \\ Baek-Jo Kim ${ }^{4} \cdot$ Maeng-Ki Kim ${ }^{1}$ \\ ${ }^{1}$ Dept. of Atmospheric Science, Kongju National University \\ ${ }^{2}$ Dept. of Geography, Kongju National University \\ ${ }^{3}$ Institute of Geographic Information Science, Kongju National University \\ ${ }^{4}$ Applied Meteorology Research Division, National Institute of Meteorological Sciences \\ (Received 10 December 2015, Revised 28 March 2016, Accepted 30 March 2016)
}

\begin{abstract}
We developed the Parameter-elevation Regressions on Independent Slopes Model(PRISM)-based Dynamical downscaling Error correction(PRIDE)-Wind speed(WS) model version 3.0 to produce highresolution $(1 \mathrm{~km})$ grid data at a monthly time scale by using observation and Regional Climate Model(RCM) wind speed data. We consequently produced monthly wind speed grid data during the observation period(2000 2014) and the future period(2021 2100) for Representative Concentration Pathway(RCP) 2 type scenarios by using the PRIDE-WS model. The PRIDE-WS model is constructed by combining the MK(Modified Korean)-PRISM-Wind, the RCM anomaly and Cumulative Density Function(CDF) fitting, basically based on Kim et al.(2016)'s algorithm applied for daily precipitation. The upper level wind $(80 \mathrm{~m}$ altitude) was estimated by Deacon equation using surface wind speed that was produced by the PRIDE-WS model. The results show that the wind speed at the upper level generally increased during the summer season while it decreased during the spring, autumn and winter seasons.
\end{abstract}

Key Words : wind speed, MK-PRISM-Wind, PRIDE-WS, statistical downscaling, high resolution, upper level wind, CDF fitting

주요어 : 풍속, MK-PRISM-Wind, PRIDE-WS, 통계적 상세화, 고해상도, 상층풍, 누적분포함수 적합

Correspondence: Maeng-Ki Kim, Dept. of Atmospheric Science, Kongju National University, 56, Gongjudaehak-ro, Gongju-si, Chungcheongnam-do, 32588, Republic of Korea, Tel: +82-41-850-8531, Fax: +82-04-856-8527, E-mail:mkkim@kongju.ac.kr 


\section{1. 서론}

최근 국내외적으로 기후변화협약의 규제와 화석 연료의 고갈, 지구온난화 현상 등 기후변화에 대 응하기 위하여 신재생 에너지 활용에 관심이 집중 되고 있다(Kwon et al., 2008). 다양한 신재생 에너 지 중 풍력 자원은 무한정한 에너지 자원이자 청 정에너지 자원이라는 점에서 경제성이 높다는 평 가를 받고 있지만(Jung et al., 2010; Song et al., 2012), 남한의 연평균 풍력 잠재 에너지량(annual average potential wind power)은 전 세계 평균보다 낮은 수준이다(Lu et al., 2009). 풍력 자원을 효과 적으로 활용하기 위해서는 풍력발전기의 설치에 앞서 최적의 입지 선정에 대한 타당성 조사가 반드 시 이루어져야하며, 그를 바탕으로 한 신뢰성 있 는 미래 기후변화에 따른 기상정보의 제공이 요구 된다(Kwon et al., 2008; Kim et al., 2011).

국립기상과학원에서는 신재생 에너지 산업 지원 에 활용하고자 고해상도의 풍력·태양-기상자원 지도를 생산하였으나(NIMR, 2010), 보다 정확한 바람 자원의 잠재성을 확인하기 위하여 관측되지 않는 지점의 잠재성 또한 요구되고 있다. 현재 남 한의 지상 관측은 약 70 여소의 유인관서(Automated Synoptic Observing System, ASOS)와 약 450여 개의 자동기상관측시스템(Automatic Weather System, AWS)으로 이루어지며, 이 관측소들은 공간 적으로 비교적 균질하게 분포해 있는 것으로 보이 나 대부분의 관측소가 $300 \mathrm{~m}$ 이하의 고도에 분포 하고(전체 관측소의 약 $87 \%$, $\mathrm{AWS}$ 의 약 50 여개의 지점이 서울과 수도권에 집중되어 있는 등 지리적 인 편중 현상이 나타나고 있다(Hong et al., 2007). 이러한 현실적인 제약으로 인해 지상 관측 자료를 이용한 공간 내삽의 필요성이 제기되어 왔다(Park et al., 2014). 기상 관측 지점이 증가함에 따라 통 계적 내삽 결과의 정확도가 향상되면서 통계적 내
삽을 이용하여 정규 격자의 기상 자료를 생산하는 다양한 연구들이 있었으나, 주로 기온과 강수량에 대한 연구였으며 풍속에 대한 연구는 상대적으로 부족한 편이었다(Park and Jang, 2008; Shin et al., 2008; Beak and Jang, 2011; Park et al., 2012; Park and Kim, 2013). 최근 제주도와 지리산을 대상으 로 풍속 내삽에 관측 상당 자료인 $\mathrm{MK}$ (Modified Korean)-PRISM(Parameter-elevation Regressions on Independent Slopes Model)을 적용해본 결과 양 호한 결과를 얻었으며(Park et al., 2014; Jang et al., 2014), Park and Jang(2015)은 기존의 MK-PRISM 을 풍속 내삽을 위해 개선하여 남한에 적용한 MK-PRISM-Wind를 개발하였다. 본 연구에서는 MK-PRISM-Wind를 적용하여 현재기후기간에 대 한 남한의 지리적 특징을 반영하여 풍속의 내삽을 진행하였다.

풍력발전기의 평균 수명은 보통 20 30년으 로 풍력발전기의 설계와 효율적인 운영을 위해 미래기간에 대한 풍력에너지의 분석이 필요하다 (Kim et al., 2014). 이미 미래 풍력에너지의 변 동성 분석에 대한 연구가 많이 진행되고 있는 국 외와 달리(Pryor et al., 2005; Pryor and Schoof, 2010; Barstad et al., 2012; Hueging et al., 2013), 국내에서는 그 이해가 부족한 실정이며 대부분 의 연구가 과거 변동성에 대한 분석에 집중되었 다(Kim et al., 2000; Kim, 2008; Kim and Byon, 2008; Byon et al., 2010; Heo et al., 2010; Kim and Kang, 2012; Lee, 2012). 최근에는 Byon et al.(2014)과 $\mathrm{Kim}$ et al.(2015)이 기후변화 시나리오 에 근거한 미래 풍속의 변동성을 분석한 바 있으 나 자료의 공간 해상도가 $12.5 \mathrm{~km}$ 로, 남한의 상세 한 공간적 특징을 반영하기에는 한계가 있다. 따 라서 본 연구에서는 보다 상세한 남한 전체의 풍 속 분포도를 산출하고자 MK-PRISM-Wind로부 터 생산된 관측 격자 자료 $(1 \mathrm{~km}$ 해상도 $)$ 를 이용 
하고, IPCC(Intergovernmental Panel on Climate Change) 5차 평가보고서에 기초하여 국립기 상과학원에서 적분한 전지구모델(AtmosphereOcean climate model of Hadley Centre Global Environment Model version 2, HadGEM2-AO) 의 자료를 경계조건으로 적용한 지역기후모델인 HadGEM3-RA(Regional climate model of Hadley Centre Global Environmental Model version 3)의 편차장과 누적분포함수(Cumulative Distribution Function, $\mathrm{CDF}$ ) 적합 과정으로 이루어진 PRIDE (PRIsm-based Dynamical downscaling Error correction) Model_V3.0(Kim et al., 2016)의 알고리즘 을 풍속에 적용하여 고해상도의 기후변화 시나리 오를 생산하였다. 이를 풍력발전기의 고도 $(80 \mathrm{~m})$ 로 변환하여 미래 상층풍의 월평균 풍속 자료를 산출 하여 미래 상층풍의 공간적 분포 특성을 분석하고 자 한다.

\section{2. 분석 자료 및 방법}

\section{1) 분석 자료}

\section{(1) 관측 자료 수집}

관측 자료를 이용한 연구에서 문제가 되는 점은 활용 가능한 자료의 기간이 짧고 공간적으로 비균 질하게 분포한다는 것이다(Hong et al., 2007). 따 라서 관측 자료는 균질하고 상세한 정규 격자의 기후 정보를 제공하기에는 부족함이 많다. 미국 에서는 이러한 문제점을 해결하기 위하여 고해상 도 격자형 기후 자료의 필요성을 인식하고 이를 생 산하기 위해 관측 자료를 기반으로 하는 PRISM 을 개발 및 개선하였으며(Daly et al., 1994; 2002; 2003; 2008; 2009), 여러 나라에서도 PRISM을 활 용하고 있다(Daly et al., 2000; 2001; Doggett et al., 2004). 우리나라에서도 PRISM의 아이디어를 기반으로 월평균 시간규모의 K-PRISM을 개발하 였으며, 이를 적용하여 $5 \mathrm{~km}$ 해상도의 기온(Hong et al., 2007) 및 강수량(Shin et al., 2008)을 생산 한 바 있다. 또한 최근 K-PRISM에 기반하여 $1 \mathrm{~km}$ 해상도의 일 시간규모의 평균·최고·최저기온과 강수량을 생산하는 MK-PRISM이 개발되었으며 (Kim et al., 2012; 2013c), IS-HYPS(Independent Slopes Hypsometric method) 기법을 적용하여 MK-PRISM이 갖고 있는 고도분포에 따른 오차를 개선한 연구가 있다(Kim et al., 2013a). 이러한 기 존의 정규 격자 기상 자료의 생산 연구는 주로 기 온과 강수량으로, 풍속에 대한 연구는 상대적으 로 매우 부족한 현황이다(Park et al., 2014). Park et al.(2014)은 MK-PRISM을 개선하여 풍속 내삽의 적용 가능성을 분석하였으며, MK-PRISM-Wind 를 개발하였다(Park and Jang, 2015).

본 연구에서는 풍속 변수에 대한 내삽으로 통계 적 다운스케일링 방법을 적용한 $1 \mathrm{~km}$ 해상도의 관 측 상당 자료인 MK-PRISM-Wind의 결과를 이용 하였고, 이후로는 MK-PRISM이라 표현하였다. 분 석 기간은 관측의 계절 사이클을 계산하기 위해 2000년부터 2014년까지의 총 15년으로 설정하였 으며, 본 연구에서는 이를 현재기후기간으로 명명 하기로 한다.

(2) 기후변화 시나리오 자료 수집

본 연구에서는 국립기상과학원에서 제공하는 400년 제어 적분된 지역기후모델(Regional climate model of Hadley Centre Global Environmental Model version 3, HadGEM3-RA)로 산출한 기후 변화 시나리오를 사용하여 분석하였다. 기후변 화 시나리오의 산출 단계는 다음과 같다. 먼저 전 지구 대기-해양 결합모델인 약 $135 \mathrm{~km}$ 해상도의 전지구모델(Atmosphere-Ocean climate model of 
Hadley Centre Global Environment Model version 2, HadGEM2-AO)로 전지구 기후변화 시나리오 를 생성하고, 이를 초기조건으로 하는 약 $12.5 \mathrm{~km}$ 해상도의 지역기후모델로 남한 영역에 대한 지역 기후변화 시나리오를 산출한다(Park et al., 2011; Baek et al., 2013). 기후변화 시나리오는 온실가스 대표농도경로(Representative Concentration Pathway, $\mathrm{RCP}$ )에 따라 총 4종으로 구성되며, RCP8.5 시나리오는 온실가스가 현재 추세로 배출되는 경 우(BAU 시나리오)이며, RCP6.0, 4.5 시나리오 는 어느 정도 온실가스 저감 정책이 실현되는 경 우, RCP2.6 시나리오는 지구 스스로 회복이 가능 한 경우이다. 여기서 RCP 시나리오 뒤의 숫자는 에너지의 평형이 온실가스 등에 의해 변화하는 영 향력의 정도를 의미하는 양으로 즉, 복사강제력을 의미한다(KMA, 2013; https://www.climate.go. kr:8005/index.html).

본 연구에서는 한반도 기후변화 시나리오 자료 중 $\mathrm{RCP} 4.5 / 8.5$ 시나리오의 2종의 시나리오를 이 용하여 고해상도의 전망 자료를 산출하였다. 분석 기간은 미래기후기간(2021 2100년, 80년)의 자 료로, 중반기간(2046 2060년, 15년)과 후반기간 (2085 2099년, 15년)으로 나누어 미래 풍력의 기 본 특성을 분석하였다.

\section{2) 분석 방법}

(1) PRIDE-WS Model_V2.0

고해상도 미래 상세 풍력 자료를 생산하는 기법 으로 본 연구에서는 Kim et al. $(2013 \mathrm{~b} ; 2016)$ 에서 제시한 PRIDE(PRIsm-based Dynamical downscaling Error correction) Model의 개념을 풍속에 적용 하여 사용하였다. PRIDE Model은 고해상도 $(1 \mathrm{~km})$ 의 격자 기반 미래기후변화 시나리오 자료를 생성 하는 모델로, 특히 관측기후 자료와 미래기후변화
시나리오를 이용하여 현재에서 미래까지 일관성 있는 자료를 산출할 수 있는 시스템이다. PRIDEWS Model의 전체적인 흐름을 Figure 1에 나타 냈다. 이 모델의 첫 번째 단계는 양질의 ASOS와 AWS 자료가 사용 가능한 최근 기간(2000 2014 년)에 대해서 MK-PRISM으로 생산한 관측 상당 풍속 자료 $(1 \mathrm{~km}$ 해상도 $)$ 를 통해 격자별 계절 사이 클을 생산하는 것이다(Figure 1a). 두 번째 단계는 지역기후모델(HadGEM3-RA)의 RCP 시나리오 자료를 관측 자료(MK-PRISM)와 동일한 기간에 대하여 분석하여 계절 사이클과 편차를 추출하고 (Figure 1b), 지역기후모델과 관측의 계절 사이클 을 비교 분석하여 지역기후모델의 계통오차를 제 거하는 것이다(Figure 1c). 이 과정에서 지역기후 모델의 변동성이 관측의 변동성에 비해 높게 나타 날 경우, 풍속 값이 0 이하의 값을 보일 수 있기 때 문에 이러한 경우는 값을 0 으로 보정하였다. 하지 만 월평균 풍속 값이 0 인 경우는 해당 달에 바람 이 한 번도 불지 않았다는 것이므로 0.1 의 값 보정 하였다. 다만 이러한 사례는 매우 드물게 발생하 였다. 여기까지가 PRIDE-WS Model_V2.0(이하 PRIDE_V2.0)이다(Figure 1d).

(2) PRIDE-WS Model V3.0

지역기후모델의 계통오차인 계절 사이클을 보 정하였다 하더라도 여전히 모델의 월 편차에 대 한 계통오차가 존재한다. 이러한 계통오차를 추가 적으로 제거하기 위하여 본 연구에서는 관측(MKPRISM)과 모델(PRIDE_V2.0) 자료의 누적확률 분포에 분위사상법(Quantile mapping)을 적용하 여 편의를 보정하였다(Figure $1 \mathrm{~g}$ ). 이 방법은 서 로 다른 두 자료가 갖고 있는 누적분포함수의 차 이를 보정하여 모델의 누적분포함수(Figure 1f) 를 관측의 누적분포함수(Figure 1e)에 근사하도 록 보정하는 방법을 말한다(Piani et al., 2010). 현 


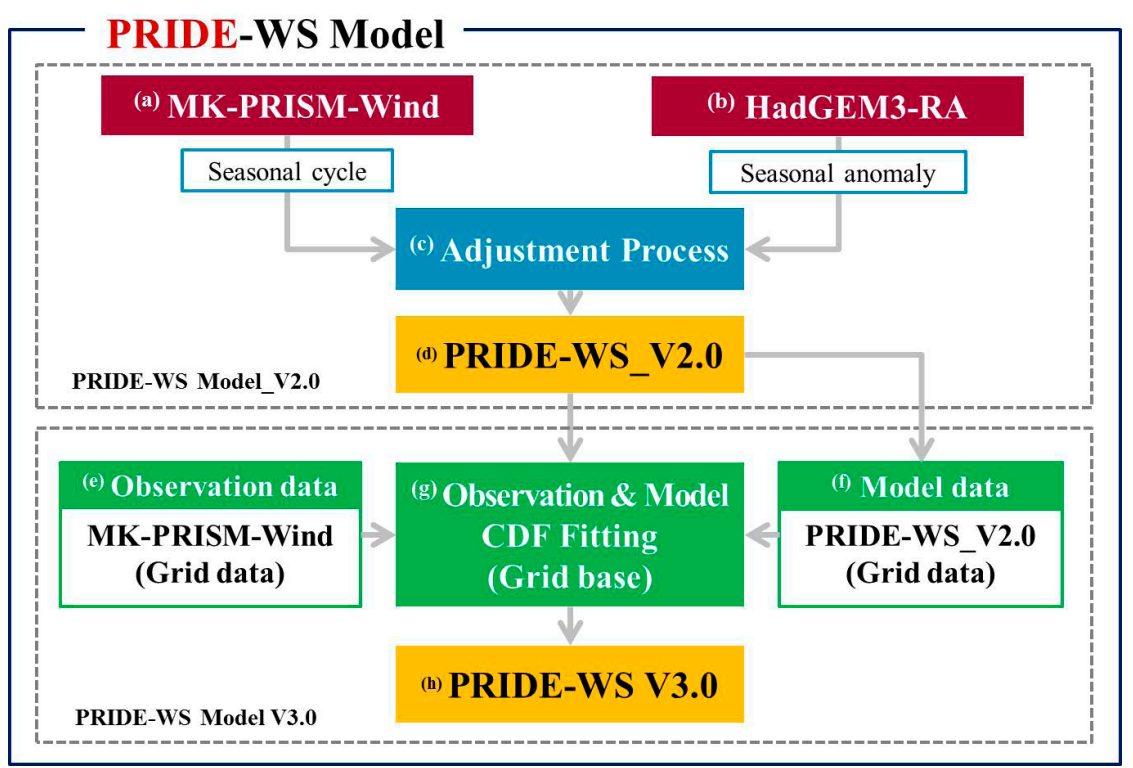

Figure 1. Schematic diagram of PRIDE-WS Model.

재 $\mathrm{KMA}(2014)$ 에서는 기온과 강수에 대해서는 이 러한 과정을 적용하여 미래 전망 자료를 생산하 고 있으나, 풍속에 대해서는 적용한 바 없다. 따라 서 본 연구에서는 유사한 알고리즘을 풍력 자료에 적용한 PRIDE-WS Model V3.0(이하 PRIDE-WS) 을 이용하여 고해상도의 풍력 자료를 생산하였다 (Figure 1h). 즉 PRIDE_V2.0은 관측의 기후값과 지역기후모델의 편차를 결합한 누적분포함수 적합 단계 이전까지의 모델을 말하며, PRIDE-WS는 관 측 자료와 앞서 생산된 PRIDE V2.0 자료의 누적 분포함수의 차이를 보정하는 모델을 말한다.

누적분포함수 적합 과정은 관측과 모델의 누적 함수분포로부터 두 함수 사이의 전환함수를 관측 기간에 대해 만들고 이를 미래기간에 적용하는 방 법이다(식 (1)). 관측 자료인 MK-PRISM의 월 풍 속 자료(2000 2014년, 총 15년)를 이용하여 월별 전이함수를 만들기에는 샘플수가 적어 전이함수가 적합하지 않다는 문제가 발생할 수 있다. 따라서 본 연구에서는 계절별로 전이함수를 설계하고 이
를 해당 월에 적용하였다. 계절별 전이함수를 계 산하고 전이함수의 모수를 추정하기 위하여 Gudmundsson et al.(2012)이 개발한 R 프로그램 패키 지를 사용하였다. 분위사상법을 기반으로 세워진 여섯 가지 전이함수 중 0 값을 계산하는 항 $(\mathrm{X} 0)$ 을 제외한 네 가지의 전이함수를 이용하였고(식 (1)), 관측과 모델의 편의를 가장 작게 하는 전이함수를 선택하여 적용하였다.

$$
\begin{aligned}
& T F_{1}: P_{0}=b \times P_{m}^{c} \\
& T F_{2}: P_{0}=a+b \times P_{m} \\
& T F_{3}: P_{0}=\left(a+b \times P_{m}\right) \times\left(1-e^{\left(-\frac{P_{m}}{\tau}\right)}\right) \\
& T F_{4}: P_{0}=b \times P_{m}
\end{aligned}
$$

검증 방법은 샘플수가 적은 단점을 보완하기 위 해 K-Fold 교차검증을 선택하였다. $\mathrm{K}$ 는 세트의 수 를 의미하며, 본 연구에서는 3 개의 세트로 분류하 여 수행하였다. 먼저, 각 세트에서 훈련기간으로 선택된 연도의 관측과 모델의 자료를 이용하여 계 절별 전이함수를 계산하였다. 검증기간의 모델 자 
료에 계절별 전이함수를 적용하여 편의 보정된 자 료를 생산하였으며, 모델의 성능을 파악하기 위한 검증기준으로 평균 절대 오차(Mean Absolute Error, MAE)와 평균 제곱근 오차(Root Mean Square Error, RMSE)를 이용하였다.

\section{(3) 풍속의 고도 보정}

풍속은 고도에 따라 변하기 때문에 풍력발전 의 분석을 위해서는 풍력발전기의 터빈이 위치하 는 고도에서의 풍속을 활용하여야 하며, 풍력발전 기 터빈의 고도는 약 $80 \mathrm{~m}$ 이상에 위치한다. 따라 서 본 연구에서는 $10 \mathrm{~m}$ 고도에서의 지상풍으로부 터 $80 \mathrm{~m}$ 고도에서의 상층풍으로 변환하기 위하여 풍력 자원 평가에 많이 사용되고 있는 Deacon 방 정식을 이용하였다(Kim et al., 2000; Kim, 2008; Kim and Byon, 2008; Byon et al., 2010; Heo et al., 2010; Kim and Kang, 2012; Lee, 2012). Deacon 방정식은 지표면의 상태에 따라 계산한 풍속 의 연직분포가 고도에 따라 로그분포를 나타내는 것을 가정한 식이며, 지형의 변화(측정 지점을 기 준으로 한 기하평균 높이)와 지표면의 거칠기 길 이(Roughness Length)에 의해 결정되는 바람에너 지의 할증계수를 이용한다(Peterson and Hennessey Jr., 1978; Hsu et al., 1994). 지면에서 고도가 높아 질수록 밀도는 낮아지는 반면, 바람 에너지는 증 가하기 때문에 바람 에너지와 높이의 관계는 대수 법칙을 따르게 된다.

풍력발전을 위한 상층풍은 지표면의 거칠기 특 성에 따라 값의 변화가 나타나기 때문에, 이를 추 정하기 위해서는 반드시 지면 거칠기 길이 자료 가 필요하다. 본 연구에서는 USGS(United States Geological Survey)에서 제공하는 식생 분류에 따 른 지면 거칠기 길이 자료를 활용하였다(KMA, 2013; https://lpdaac.usgs.gov/dataset_discovery/ modis/modis_products_table).

\section{3. 분석 결과}

\section{1) 현재기후기간}

(1) MK-PRISM과 지역기후모델의 비교 현재기후기간(2000 2014년)에 대한 관측 상 당 자료인 MK-PRISM과 지역기후모델의 평균 풍 속을 비교 분석하였다. Figure 2 는 현재기후기간 에 대한 월평균 풍속의 기후값을 지역기후모델(a), MK-PRISM(b)에 대해 각각 나타낸 것이다. $1 \mathrm{~km}$ 해상도의 MK-PRISM과 $12.5 \mathrm{~km}$ 의 해상도의 지 역기후모델은 내륙보다 해안가 및 제주도 지역에 서 풍속이 강하게 나타나는 공통점을 갖지만, 정 량적인 강도에서 차이를 보이고 있다. 지역기후모 델에서는 서해안지역과 남해안지역에서 평균 $7 \mathrm{~m} /$ $s$ 의 강한 풍속이 넓게 분포하고 있으나, 이와 달 리 MK-PRISM에서는 평균 $4 \mathrm{~m} / \mathrm{s}$ 의 약한 풍속 분 포를 보인다. 또한 MK-PRISM은 지역기후모델보 다 산악 등 지형의 효과가 잘 반영되어 내륙지역 에 비해 태백산맥과 소백산맥에서 강한 풍속 분포 를 보이고 있다. 제주도지역을 살펴보면 지역기후 모델은 $12.5 \mathrm{~km}$ 의 해상도로 인해 제주도지역 전체 에 대해 풍속이 강한 분포를 보이고 있으나, MKPRISM은 $1 \mathrm{~km}$ 의 해상도로 상세화 됨에 따라 편서 풍의 영향을 받는 풍상측에서의 풍속이 비교적 강 하게 나타나고, 나머지 내륙지역에서는 약한 풍속 의 분포를 보이고 있다. 따라서 공간 해상도가 높 은 MK-PRISM에서 풍속의 분포가 세밀해지고 국 지적인 지형구조가 반영되어 나타남을 알 수 있 다. 이는 공간해상도가 높은 MK-PRISM에서 지 형의 기복이 명확하게 묘사되기 때문이다. 이로써 MK-PRISM은 산악효과 및 고도 등의 지리적 특징 이 잘 반영된 고해상도 관측 자료라 판단할 수 있 다.

Figure 3은 현재기후기간(2000 2014년)에 대하 


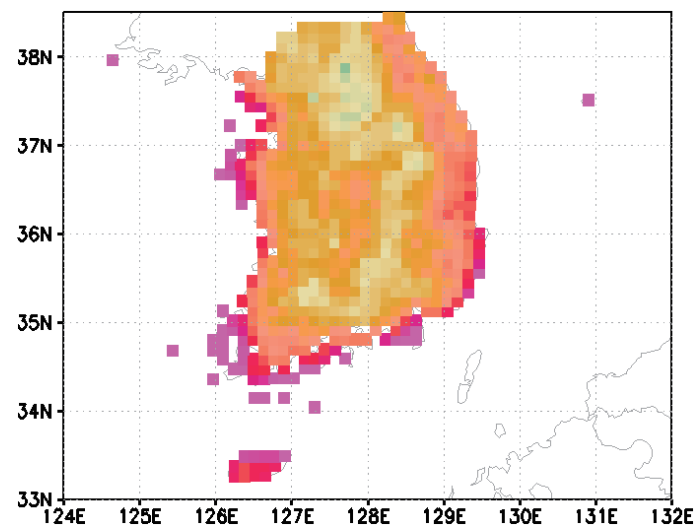

(a) HadGEM3-RA

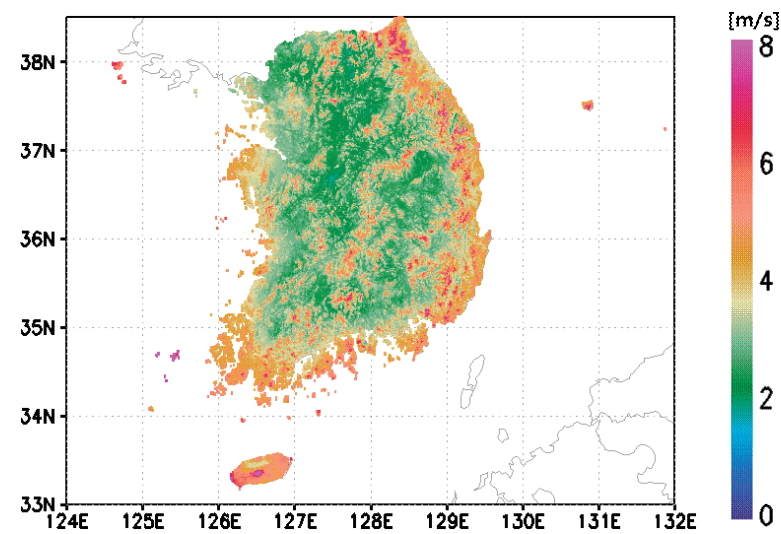

(b) MK-PRISM

Figure 2. Spatial distribution of climatology in (a) HadGEM3-RA and (b) MK-PRISM during observation period (2000-2014, 15years) (unit: $\mathrm{m} / \mathrm{s})$.

여 MK-PRISM과 지역기후모델의 계절 사이클의 차이를 나타낸 것이다. MK-PRISM과 지역기후모 델의 계절 변동성은 봄철, 겨울철에는 풍속이 강 하고 여름철, 가을철에는 풍속이 약한 특성이 유 사하게 나타난다. 지역기후모델(빨강색 음영의 상 단)의 연평균 풍속(약 $4.80 \mathrm{~m} / \mathrm{s}$ )과 $\mathrm{MK}-\mathrm{PRISM}$ (검 정 실선)의 연평균 풍속(약 $3.48 \mathrm{~m} / \mathrm{s})$ 은 약 $1.3 \mathrm{~m} / \mathrm{s}$ 의 평균오차(mean bias)를 보이며, 계절별로는 여 름철보다 겨울철에 더 큰 평균오차를 보인다. 이
러한 평균오차는 지역기후모델이 가지는 계통적인 오차로 판단되며, 미래 풍력 잠재성의 평가에 앞 서 보정이 되어야 할 부분이다.

(2) 누적분포함수 적합 및 검증 결과

본 연구에서는 보다 신뢰성 있는 분석을 위해 누 적분포함수 적합 방법을 적용하여 PRIDE Model 을 개선하였다. 남한 전체 격자에 대해 누적분포 함수 적합을 적용하여 검증한 결과, 보정이 잘 이

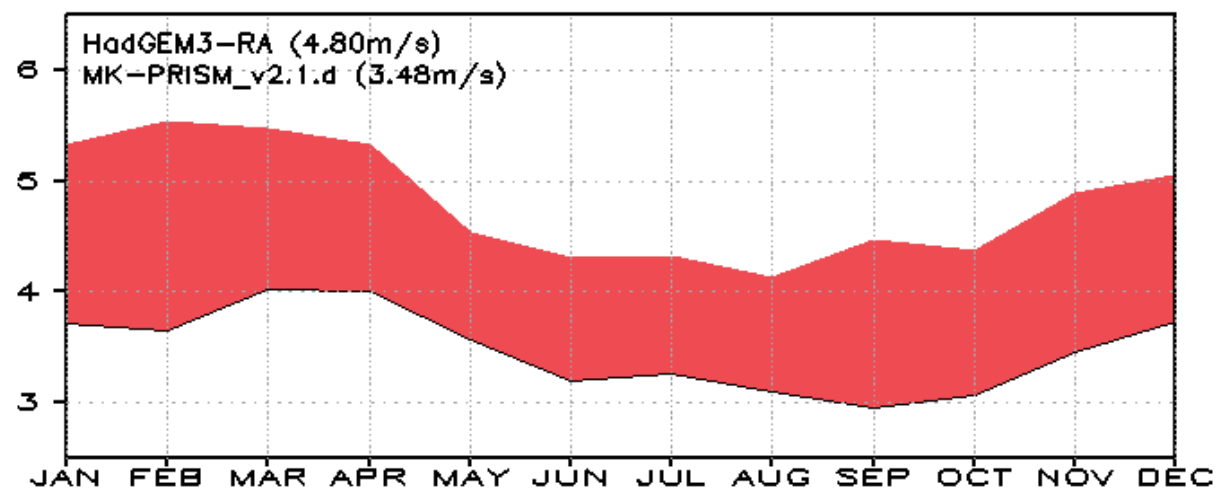

Figure 3. Time series of seasonal cycle of MK-PRISM model (lower solid line) and HadGEM3-RA model (upper solid line) during the observation periods (2000-2014, 15 years). Red areas indicate that wind speed in HadGEM3-RA is stronger than MK-PRISM (unit: $\mathrm{m} / \mathrm{s}$ ). 
루어진 격자도 있지만 그렇지 않은 격자도 있었 다. 그 원인으로는 첫째, 샘플수가 적음에 따라 훈 련기간이 짧기 때문에 설계된 전환함수가 검증 기간에 대해 적용하기 적합하지 않은 경우가 있 다. 둘째, 사용한 자료가 월평균 풍속으로 풍속 값 의 범위가 좁고 어느 특정 범위대의 풍속이 집중 되어 양 극의 범위대에 적합한 함수를 설계하는데 어려움이 있다. Figure 4는 3-Fold 교차검증의 결 과를 보여주며, 관측(MK-PRISM)과 누적분포함 수 적합 전 모델(PRIDE V2.0), 그리고 누적분포 함수 적합 후 모델(PRIDE-WS)의 경험적 누적분 포함수(Empirical CDF, ECDF)와 QQ(QuantileQuantile)-plot으로, 보정이 잘 이루어진 샘플격자 (Figure $4 \mathrm{a}$ and $4 \mathrm{~b}$ )와 보정이 잘 이루어지지 않은

(a)

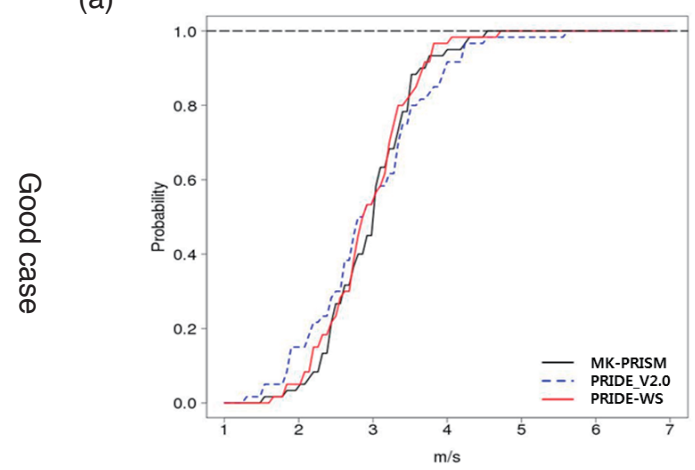

(c)

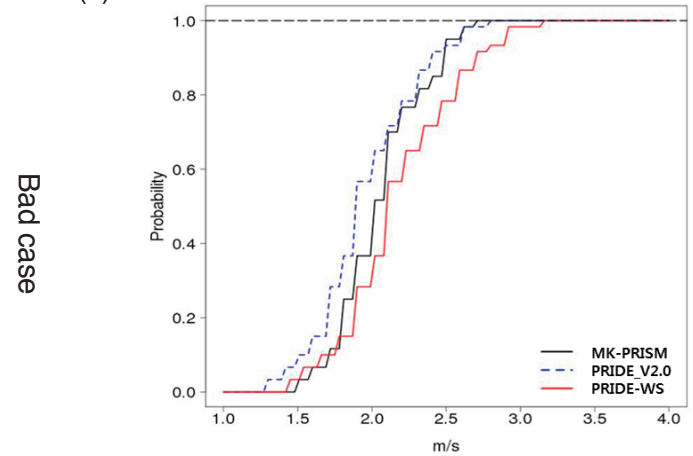

샘플격자(Figure $4 \mathrm{c}$ and $4 \mathrm{~d}$ )를 각각 나타낸다. 보 정이 잘 이루어진 샘플의 경험적 누적분포함수를 비교해보면(Figure 4a), 보정 후(PRIDE-WS, 적색 실선)의 곡선이 보정 전(PRIDE_V2.0, 청색 점선) 의 곡선보다 관측(MK-PRISM, 검정색 실선)의 곡 선을 잘 따라가고 있다. 양극단에서도 보정이 잘 이루어졌으므로, 전이함수가 적합하게 설계되었다 고 판단된다. QQ-plot에서도 보정 후가 보정 전보 다 $1: 1$ 직선 위에 있는 것을 확인할 수 있다Figure $4 \mathrm{~b})$. 반면 보정이 잘 이루어지지 않은 샘플의 경험 적 누적분포함수는 보정 후의 곡선이 보정 전의 곡 선과 유사하였고, 관측과의 오차가 보정 전보다 보 정 후에서 더 크게 모의하였다(Figure 4c). QQplot에서도 보정 후가 보정 전보다 1:1 직선에 더 (b)

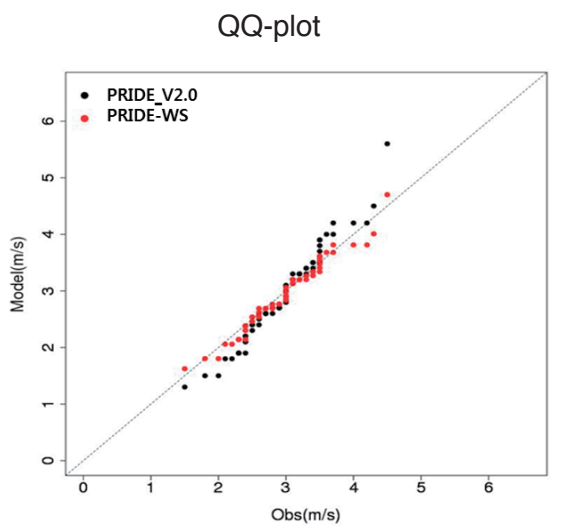

(d)

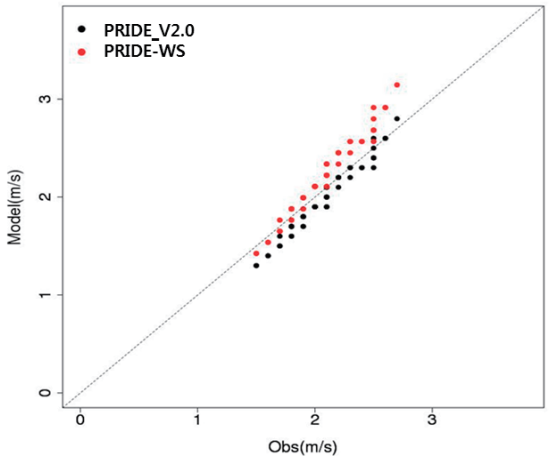

Figure 4. Three-FOLD cross-validation for the best correction case (upper) and the worst correction case (lower). Left: Empirical Cumulative Density Function comparison. Right: QQ-plot. 
벗어났다(Figure $4 \mathrm{~d}$ ). 이러한 부분은 향후 개선이 필요하다.

Table 1 은 교차 검증한 자료의 월별 평균 제곱 근 오차(RMSE)와 평균 절대 오차(MAE)를 나타 낸 것이다. 모든 달에서 보정 전(PRIDE_V2.0)보 다 보정 후(PRIDE-WS)의 결과가 조금 더 좋았으 며, 특히 1 월에서 보정이 잘 이루어졌다. 값이 큰 차이가 나지 않는 이유는 보정 전만으로도 계절 사 이클의 계통오차가 제거되기 때문이기도 하고, 월 풍속의 단위로 수행하여 풍속 값의 범위가 작아 어 느 특정 범위대의 풍속이 집중되어 나타나기 때문 이다.

전이함수를 적용하여 보정이 잘 이루어진 격자 는 그 결과를 적용하였으나, 그렇지 않은 격자는 PRIDE_V2.0의 기존 결과를 적용하여 오차를 최 소화 하는 방법으로 진행하였다. PRIDE_V2.0의 결과 또한 모델의 계통오차가 제거되었으며 관측 의 지형효과가 잘 반영되었기 때문에 단순 내삽 또 는 원시 자료의 결과보다 오차가 작으며, 검증보 다 더 많은 자료(현재기후기간, 총 15년)로 전이
함수를 설계하였기 때문에 신뢰할 수 있다고 판단 된다.

\section{(3) PRIDE-WS와 MK-PRISM의 비교}

Figure 5a는 현재기후기간(2000 2014년)에 대한 PRIDE-WS의 월평균 풍속 공간분포이다. $12.5 \mathrm{~km}$ 해상도의 지역기후모델 자료(Figure $2 \mathrm{a}$ ) 를 $1 \mathrm{~km}$ 해상도의 MK-PRISM(Figure 2b)에 적용 하여 산출한 PRIDE-WS(Figure 5a)는 복잡한 남한 지형이 반영된 풍속의 분포 특성이 명확히 나타나 는 고해상도 미래 전망 시나리오로 재생산되었다. PRIDE-WS의 결과는 비록 MK-PRISM의 결과와 절대적인 풍속 값은 일치하지 않지만 유사한 공간 특성을 보이며, 지역기후모델이 가진 계통 오차가 잘 보정되었음을 확인할 수 있다.

Figure 5b는 현재기후기간(2000 2014년)의 PRIDE-WS와 MK-PRISM의 차이를 나타낸 것 이다. 지역기후모델과 MK-PRISM 두 모델에 서 약 $1.3 \mathrm{~m} / \mathrm{s}$ 의 오차를 보이던 Figure 3 과는 달 리 PRIDE-WS로 수행한 결과, PRIDE-WS와

Table 1. Quantitative results of Cross-Validation.

\begin{tabular}{c|c|c|c|c}
\hline \hline \multirow{2}{*}{ Month } & \multicolumn{2}{|c|}{ RMSE } & \multicolumn{2}{c}{ MAE } \\
\hline 1 & PRIDE_V2.0 & PRIDE-WS & PRIDE_V2.0 & PRIDE-WS \\
2 & 0.32 & 0.28 & 0.23 & 0.19 \\
3 & 0.17 & 0.16 & 0.14 & 0.14 \\
4 & 0.20 & 0.17 & 0.16 & 0.15 \\
5 & 0.20 & 0.19 & 0.15 & 0.11 \\
6 & 0.15 & 0.14 & 0.12 & 0.12 \\
7 & 0.17 & 0.15 & 0.14 & 0.13 \\
8 & 0.19 & 0.17 & 0.15 & 0.12 \\
9 & 0.16 & 0.15 & 0.13 & 0.25 \\
10 & 0.35 & 0.32 & 0.27 & 0.12 \\
11 & 0.16 & 0.15 & 0.13 & 0.13 \\
12 & 0.17 & 0.16 & 0.14 & 0.15 \\
\hline AVE & 0.20 & 0.19 & 0.17 & 0.14 \\
\hline \hline
\end{tabular}


MK-PRISM의 연평균 풍속은 유사하게 나타났 다. $1 \sim 4,6,8,11$ 월에는 음의 편의를 보였고, 나 머지 달에서는 양의 편의를 보였다. 두 모델은 최 대 $0.1 \mathrm{~m} / \mathrm{s}$ 의 미소한 평균 오차 값을 보였으며, PRIDE-WS를 통해 지역기후모델이 갖고 있는 계 통 오차를 감소시키면서 신뢰도가 향상된 고해상 도의 풍속 자료를 산출할 수 있게 되었다. 하지만 비록 작은 오차라도 PRIDE-WS를 이용한 분석 시 편의를 고려하여 사용해야 한다.

\section{2) PRIDE-WS 결과}

미래의 풍력 자원 변화를 살펴보기 위하여 기 간을 중반기간과 후반기간으로 구분하여 분석 을 진행하였다. 가능한 현재기후기간이 15년 (2000 2014년)이므로, 미래기후기간을 중반기간 15년(2046 2060년), 후반기간 15년(2085 2099 년)으로 구분하여 진행하였다.

미래기후기간의 RCP 시나리오별 변화량을 살 펴보기에 앞서, 현재기후기간에 대한 월평균 풍속 의 기후값을 계절별로 Figure 6에 제시하였다. 모 든 계절에서 해안지역과 도서지역, 산악지역에서 강한 풍속을 보였다. 이에 비해 내륙지역에서의 풍속은 그리 강하지 않은 것으로 나타나는데, 이
는 내륙에서의 복잡한 지형으로 인한 영향이 상층 풍까지 영향을 미친 것으로 설명된다. 특히 봄철 과 겨울철은 상대적으로 여름철과 가을철에 비해 풍속이 강한 우리나라의 전형적인 풍속 특징을 보 였다. 이와 같은 특징은 해양과 육지의 비열 차이 에 의한 것으로, 여름철은 육지의 온도 상승으로 인해 해양과 육지의 온도차가 감소하는 반면, 겨 울철은 해양보다 육지가 훨씬 한랭하여 풍속의 차 이가 증가하기 때문이며, 특히 우리나라는 해양 의 면적보다 육지의 면적이 훨씬 더 넓으므로 계 절별로 풍속의 차이가 큰 특징을 보인다(Byon $e t$ al., 2011). 우리나라는 몬순 기후 특성상 풍속의 계절 변화가 매우 큰 폭으로 발생한다. 그 중 겨 울철은 다른 계절에 비해 산악지역에서의 강한 풍 속과 내륙지역에서의 약한 풍속의 차이가 더욱 뚜 렷하게 나타나며, 이는 대기안정도와 관련이 있음 을 Lee(2009)에서 보인바 있다. Lee and Kimura (2001)는 대기안정도가 중규모 기상장의 강도를 결정하는 중요한 요인임을 설명하였으며, 특히 대 기안정도가 강할 경우 지형강제력이 강하게 작용 한다고 하였다. 따라서 겨울철에 대기안정도가 높 음에 따라 남한에서의 지형강제력이 강하게 나타 나고, 강한 지형강제력은 내륙지역과 산악지역의 (a)

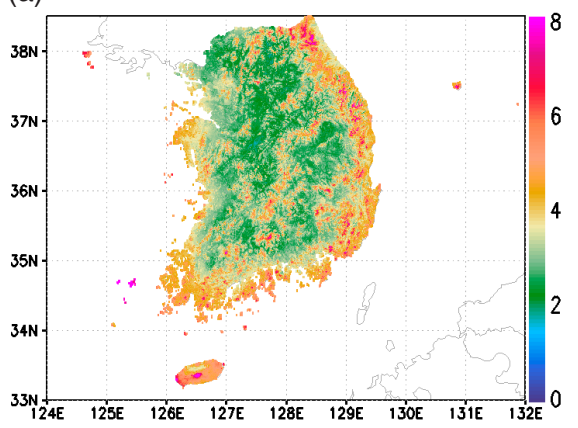

(b)

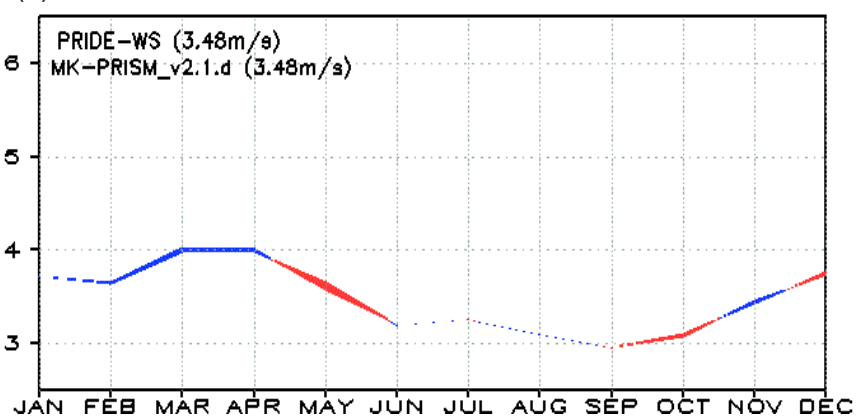

Figure 5. Spatial distribution of observation period (2000-2014, 15years) climatology in (a) PRIDE-WS model and (b) seasonal cycle (unit: $\mathrm{m} / \mathrm{s}$ ). Red and blue shading areas in (b) represent over and under estimation of PRIDE-WS model compared to MK-PRISM (unit: $\mathrm{m} / \mathrm{s}$ ). 
풍속 차이를 크게 한다고 설명하였다(Lee, 2009).

Figure 7은 현재기후기간 및 RCP 2종의 미래 시 나리오를 이용하여 추정한 상층풍의 연평균 시계 열을 나타낸 것이다. 21 세기 초반에서 후반으로 진행할수록 RCP 2종의 상층풍 모두 시간에 따라 감소하는 경향 $(-0.00060 / \mathrm{yr},-0.00126 / \mathrm{yr})$ 이 나타 났다. 현재(2001 2010년) 대비 미래의 연대별 증 감률을 나타낸 Table 2에서 보이듯 RCP4.5 시나리 오의 2050 년대와 RCP8.5 시나리오의 2020, 2080 , 2090년대를 제외한 모든 연대의 RCP 2종 모두에 서 풍속이 증가하는 경향을 보이며, RCP4.5 시나 리오의 2040 년대에서 $2.34 \%, \mathrm{RCP} 8.5$ 시나리오의
2040년대에서 3.19\%로 RCP 2종 모두 중반기간에 서 현재 대비 미래 풍속의 증가경향이 가장 크게 나타나는 것을 알 수 있다.

Figure 8과 Figure 9는 계절별 월평균 풍속의 현 재 대비 미래 변화량의 공간분포로 각각 RCP4.5 시나리오와 RCP8.5 시나리오를 적용한 결과이다. 미래의 계절적인 특징은 여름철은 대부분의 지역 에서 풍속이 증가하고 봄철, 가을철은 풍속이 감 소하는 경향을 보인다. 겨울철의 경우 RCP8.5 시 나리오의 중반은 현재 대비 풍속이 증가하지만 후 반에는 현재 대비 감소하며, 본 논문에는 제시하 지 않았지만 미래로 갈수록 감소하는 선형 경향성 (a) MAM

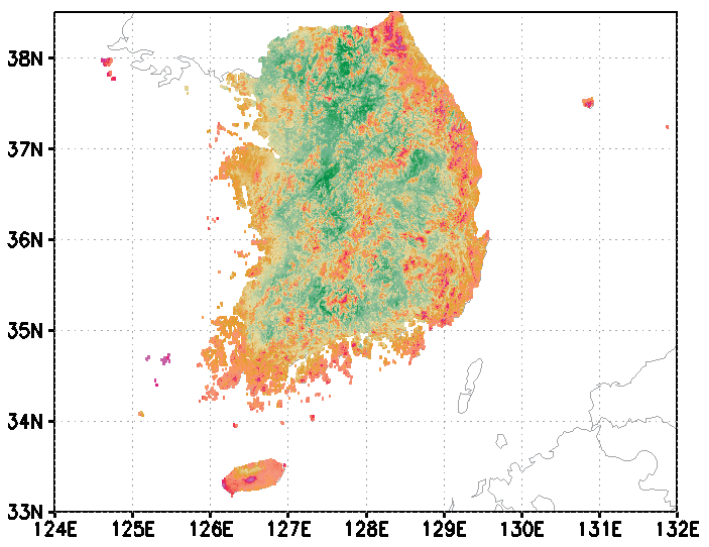

(c) SON

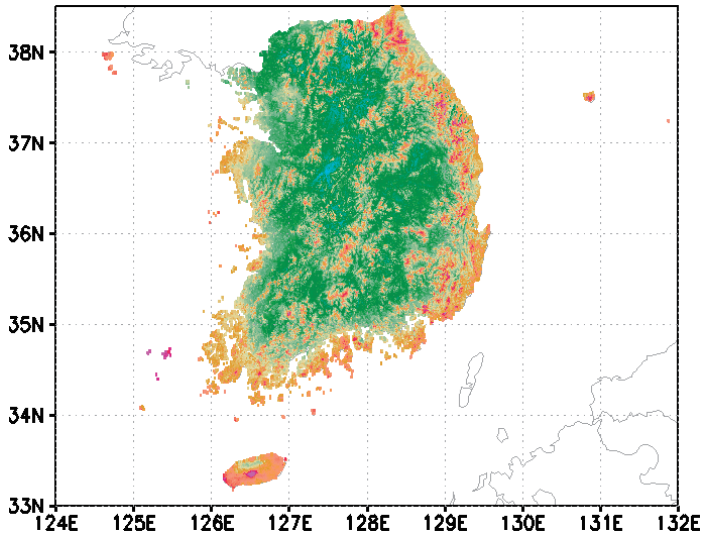

(b) JJA

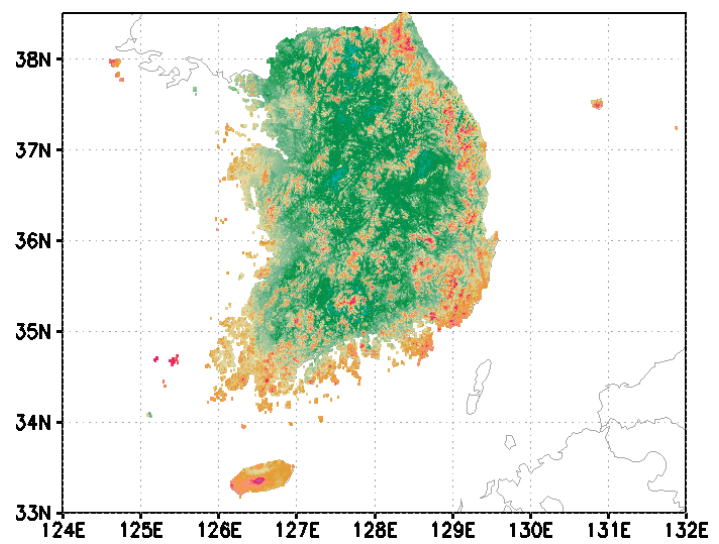

(d) DJF

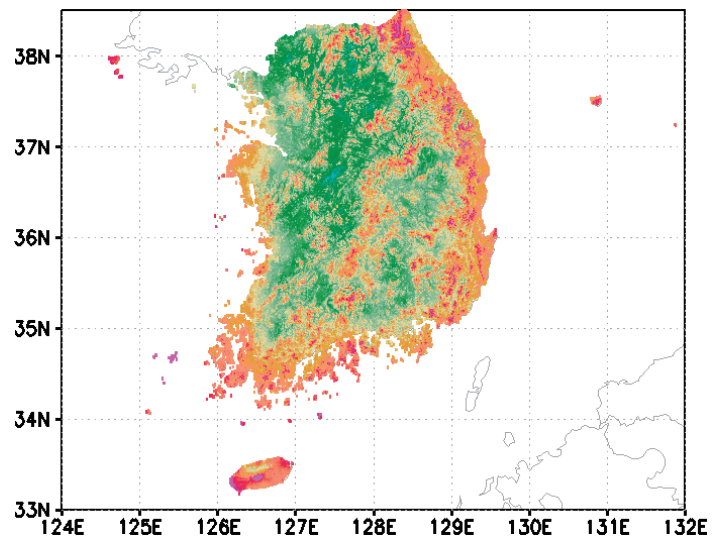

Figure 6. Spatial distribution of monthly mean wind speed during observation period (2000-2014, 15years) for (a) spring, (b) summer, (c) fall and (d) winter (unit: $\mathrm{m} / \mathrm{s}$ ). 


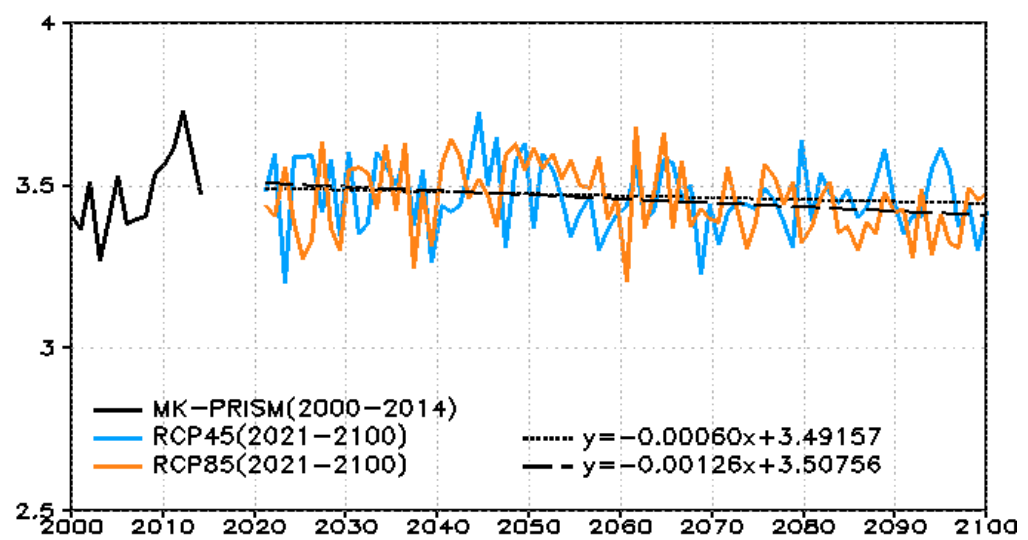

Figure 7. Time series of annual mean upper level $(80 \mathrm{~m})$ wind speed during observation period and two kinds of RCP scenario data (unit: $\mathrm{m} / \mathrm{s}$ ).

Table 2. Annual mean wind speed percentage change by RCP scenarios versus observation period (MK-PRISM).

\begin{tabular}{c|c|c|c|c|c|c|c|c}
\hline \hline & $2020 s$ & $2030 s$ & $2040 s$ & $2050 s$ & $2060 s$ & $2070 s$ & $2080 s$ & $2090 s$ \\
\hline RCP4.5 & $1.87 \%$ & $0.79 \%$ & $2.34 \%$ & $0.00 \%$ & $0.35 \%$ & $0.18 \%$ & $1.02 \%$ & $0.76 \%$ \\
RCP8.5 & $-0.30 \%$ & $1.37 \%$ & $3.19 \%$ & $1.58 \%$ & $1.08 \%$ & $0.15 \%$ & $-0.82 \%$ & $-1.43 \%$ \\
\hline \hline
\end{tabular}

을 보였다. 이는 현재에는 봄철, 겨울철에 풍속이 강하고 여름철, 가을철에 약한 풍속을 보이는 우 리나라의 계절적 분포를 고려하였을 때, 21 세기 미래에는 현재보다 계절 사이클의 진폭이 감소한 다는 것을 의미한다. 현재 대비 미래의 변화량을 계절별로 상세히 살펴보면 다음과 같다.

먼저 봄철의 경우 RCP4.5/8.5 시나리오 모두 해 안과 밀접한 아주 미소한 몇몇 지점에서만 풍속이 증가하고, 그 외의 지역은 풍속의 감소경향이 다 른 계절에 비해 강한 강도로 넓게 분포하는 모습을 볼 수 있다. 제주도와 도서지역에서도 풍속의 감 소 정도가 강하게 나타난다. 이 분포 경향은 가을 철에도 유사하게 나타나지만 그 강도는 약간의 차 이를 보인다. 봄철의 RCP4.5/8.5 시나리오와 가을 철의 RCP8.5 시나리오는 중반기간보다 후반기간 에서의 감소 경향이 더 크게 나타나지만, 이와 반 대로 RCP4.5 시나리오의 가을철은 후반기간보다
중반기간에서 더 강한 감소 경향을 보여 중반기간 에서 후반기간으로 진행할수록 풍속의 감소 경향 이 약해짐을 알 수 있다.

겨울철은 RCP8.5 시나리오의 중반기간을 제외 한 나머지 기간의 대부분의 지역에서 풍속이 감소 하는 분포를 보인다. 이러한 풍속의 분포 양상은 해안과 밀접한 몇몇 지점에서만 풍속이 증가하는 분포를 보인 봄철, 가을철과는 달리, 겨울철은 풍 속의 증가 분포가 해안과 밀접했던 지역에서 서해 안지역과 동해안지역 안까지 좀 더 넓게 퍼진 것을 확인할 수 있다. 특징적인 것은 겨울철 RCP8.5 시 나리오의 후반기간에서 내륙지역을 제외한 서해안 지역과 동해안지역에서의 풍속의 증가 경향이 다 른 기간에 비해 강하게 나타난다는 것이다.

다른 계절과 다르게 여름철은 오히려 풍속이 증 가하는 분포를 보인다. 하지만 두 시나리오 모두 중반기간에서 후반기간으로 진행할수록 증가경향 
(a)

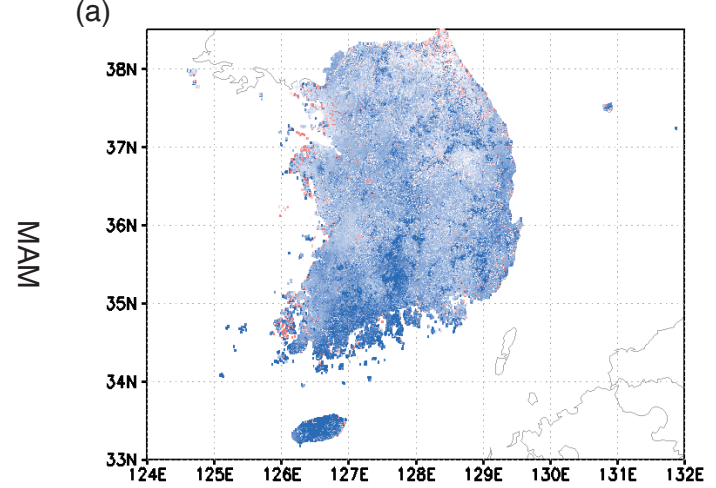

(c)

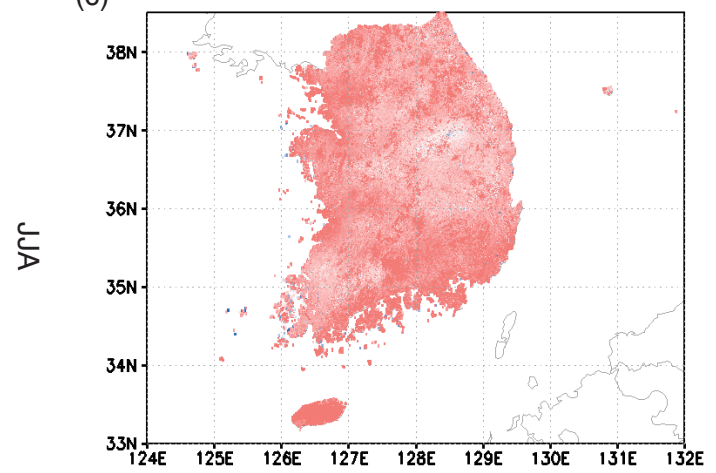

(e)

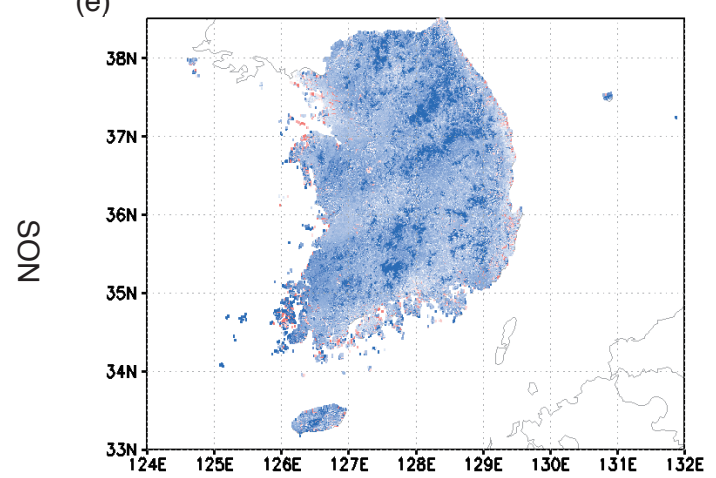

(g)

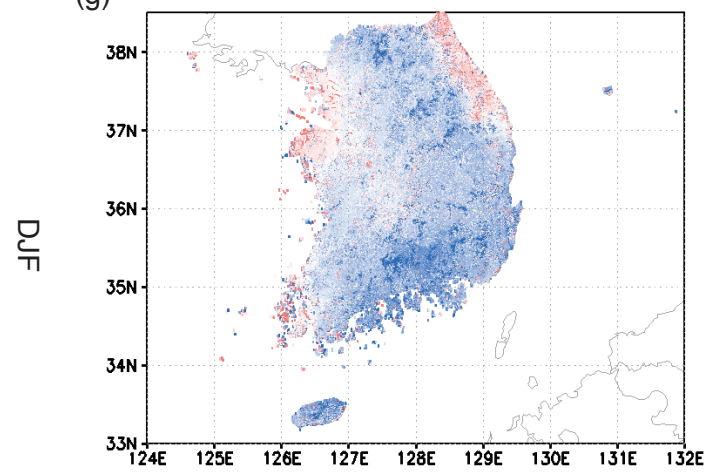

(b)

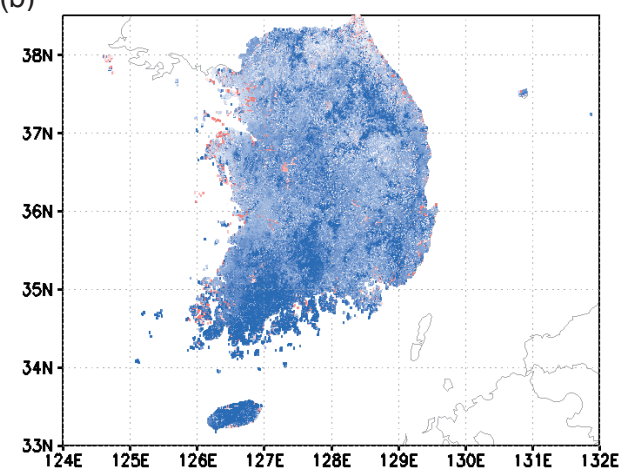

(d)

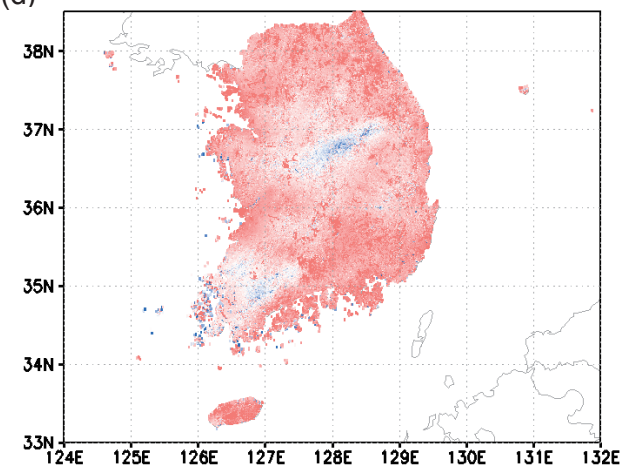

[m/s]

0.3

0.2

0.1

0

$-0.1$

$-0.2$

$-0.3$

Figure 8. Spatial distribution of wind speed difference between RCP4.5 scenario and observation period (20002014, 15years) (unit: m/s). 
(a)

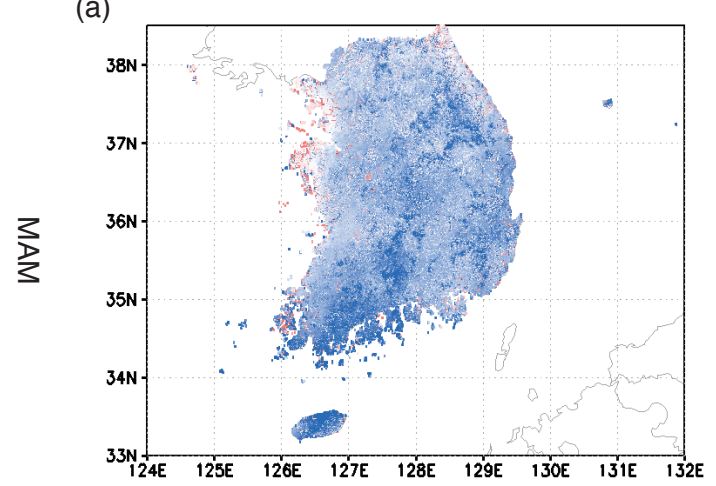

(c)

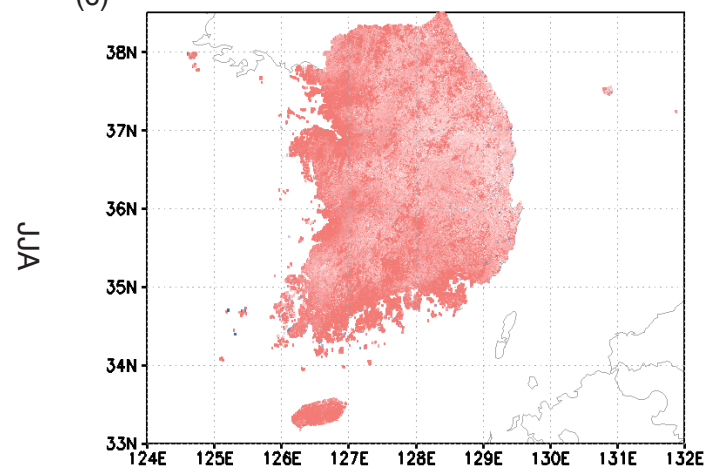

(e)

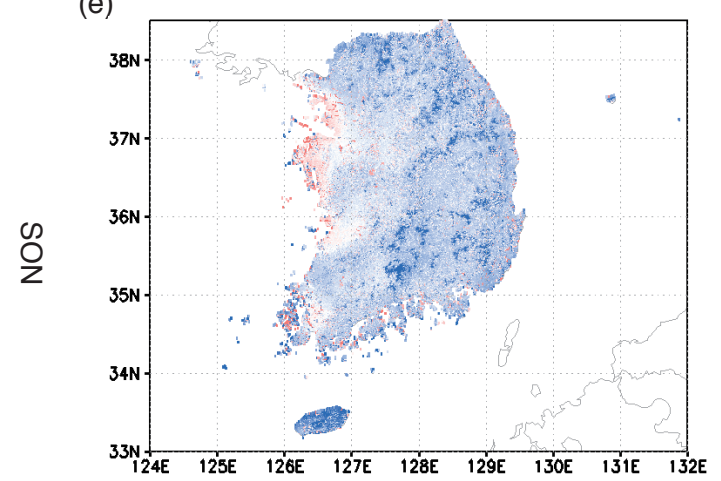

(g)

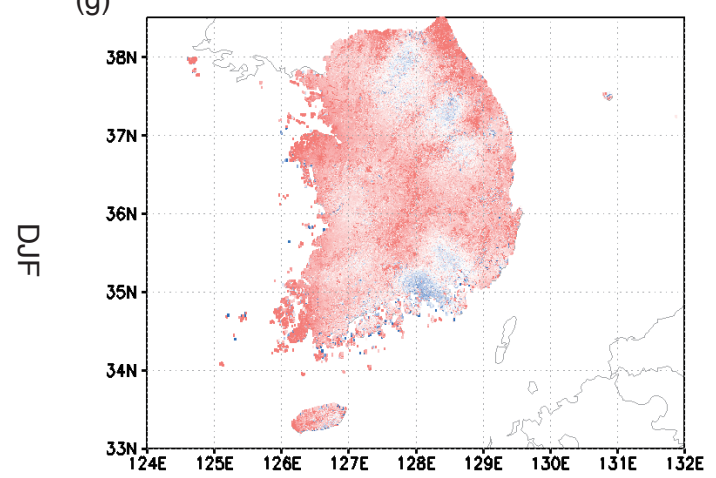

(b)

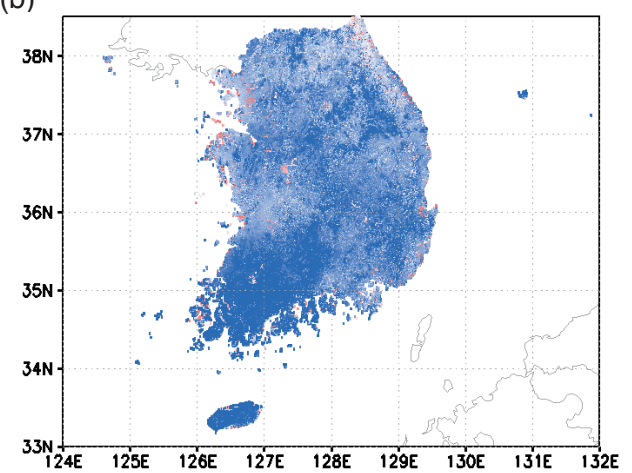

(d)

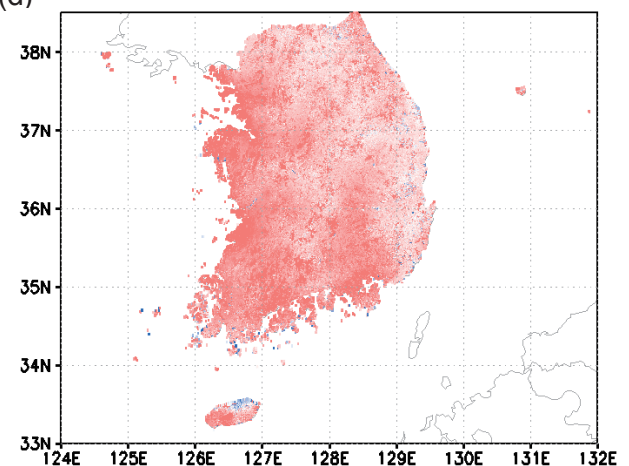

(f)

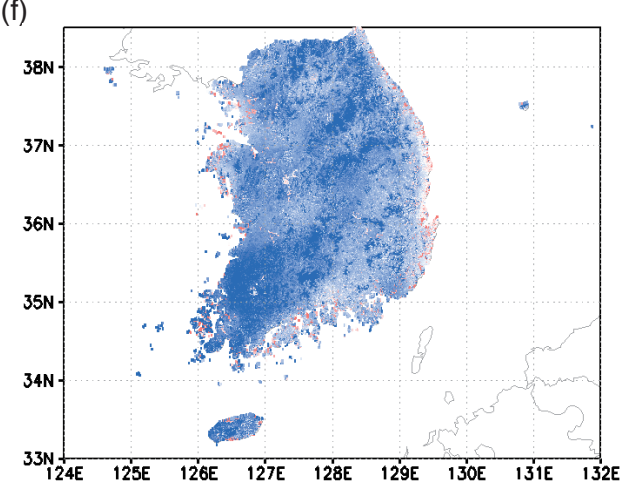

(h)

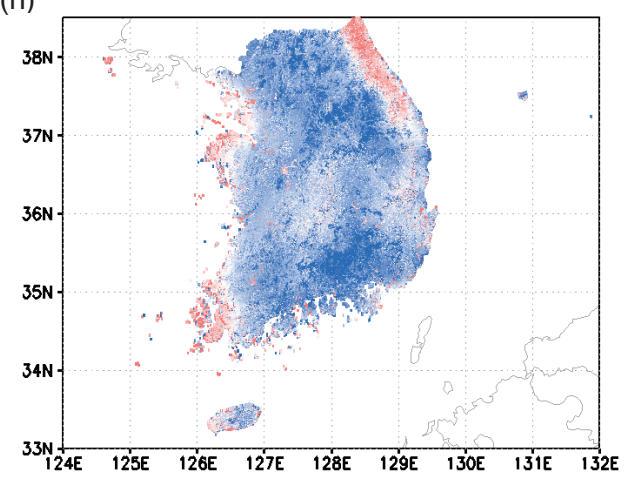

[m/s]

0.3

0.2

0.1

0

$-0.1$

$-0.2$

$-0.3$

Figure 9. Spatial distribution of wind speed difference between RCP8.5 scenario and observation period (20002014, 15years) (unit: $\mathrm{m} / \mathrm{s}$ ). 
Table 3. Seasonal climatology percentage change by RCP scenarios of two periods relative to observation period (MK-PRISM).

\begin{tabular}{c|c|c|c|c}
\hline \hline \multirow{2}{*}{} & \multicolumn{2}{|c|}{ RCP4.5 } & \multicolumn{2}{c}{ RCP8.5 } \\
\cline { 2 - 5 } & $2046-2060$ & $2085-2099$ & $2046-2060$ & $2085-2099$ \\
\hline MAM & $-3.39 \%$ & $-4.73 \%$ & $-3.43 \%$ & $-6.12 \%$ \\
JJA & $7.11 \%$ & $4.83 \%$ & $7.41 \%$ & $5.99 \%$ \\
SON & $-4.74 \%$ & $-0.81 \%$ & $-2.47 \%$ & $-6.25 \%$ \\
DJF & $-1.67 \%$ & $-1.78 \%$ & $3.27 \%$ & $-3.07 \%$ \\
\hline \hline
\end{tabular}

이 줄어들어, 이는 미래로 갈수록 풍속의 증가경 향이 약해짐을 의미한다.

시나리오의 계절적 특성을 정량적으로 확인한 결과, 남한은 평균적으로 여름철에 증가하고 봄 철, 가을철, 겨울철에 감소하는 경향을 보인다 (Table 3). RCP8.5 시나리오 중반기간의 여름철에 서 $7.41 \%$ 의 가장 큰 증가율을 보이며, RCP8.5 시 나리오 후반기간의 가을철에서 $-6.25 \%$ 의 가장 큰 감소율을 보인다.

종합적으로 현재기후기간의 MK-PRISM에서 4 계절 중 봄철에서 가장 강한 풍속 값을 보이지만, 미래로 진행할수록 봄철의 풍속이 큰 감소율을 보 이고 있어 봄철과 겨울철은 풍속이 강하고 상대적 으로 여름철과 가을철은 풍속이 약하게 나타나는 우리나라의 계절성을 약화시키는 방향으로 진행함 을 알 수 있다.

\section{4. 요약 및 결론}

본 연구에서는 고해상도 $(1 \mathrm{~km})$ 풍력 기상자원 정 보를 제공하기 위하여 고해상도 격자형 미래 기 후변화 전망 자료를 생산하는 통계적 상세화 모 델인 PRIDE-WS Model V3.0(이하 PRIDE-WS) 을 개발하였다. PRIDE-WS는 PRIDE-WS Model $\mathrm{V} 2.0$ (이하 PRIDE_V2.0)의 계통오차를 누적분
포함수 적합을 적용하여 모델 자료의 누적확률 분포의 편의를 보정한 모델이다. 본 연구에서는 PRIDE-WS를 사용하여 현재기후기간 및 미래기 후기간에 대한 남한의 월별 지상( $10 \mathrm{~m}$ 고도) 풍속 격자 자료를 생산하였으며, Deacon 방정식을 이 용하여 풍력발전기 터빈의 고도인 $80 \mathrm{~m}$ 에서의 상 층풍을 산출하였다.

지역기후모델이 생산하는 $12.5 \mathrm{~km}$ 해상도의 자 료는 남한의 국지적 현상을 설명하기에는 다소 무 리가 있으나, PRIDE-WS가 생산한 $1 \mathrm{~km}$ 격자 자 료는 고도 등의 지형효과를 매우 잘 반영하여 지 형효과에 따른 풍속의 변동과 산악지형에서의 강 한 풍속을 잘 설명하는 것으로 나타났다. 특히, 지 역기후모델이 갖고 있던 $1.3 \mathrm{~m} / \mathrm{s}$ 의 평균오차(mean bias)가 누적분포함수 적합을 통하여 상당부분 보 정되었으며, 그 결과 PRIDE-WS의 기후 평균 풍 속 $(3.48 \mathrm{~m} / \mathrm{s})$ 이 MK-PRISM $(3.48 \mathrm{~m} / \mathrm{s})$ 과 거의 유사 하게 나타났다.

본 연구에서는 국립기상과학원에서 생산한 지역기후모델의 RCP 기후변화 시나리오 자료 (RCP4.5/8.5, 2종)를 PRIDE-WS에 적용하여 상층 풍의 미래변화를 분석하였다. 그 결과, $\mathrm{RCP} 2$ 종 의 시나리오 모두에서 전반적으로 여름철에 풍속 이 증가하고 봄철, 가을철, 겨울철에 풍속이 감소 하는 경향을 보였다. 이러한 특성은 관측 기후값 의 계절 사이클(강한 겨울철 풍속과 약한 여름철 
풍속)을 고려해 볼 때, 21 세기 미래에는 현재보다 계절 사이클의 진폭이 감소한다는 것을 의미한다. 이러한 특성은 지역에 따라 큰 차이가 없이 남한 전체에서 발생하는 특성을 보였다.

향후 미래 상층풍의 계절 사이클의 진폭의 크기 가 변화하는 원인을 파악하기 위해서는 여러 기후 모델의 시나리오를 분석하여 일관성이 있는지를 고찰해야 할 것으로 보이며, 그 기작은 무엇인지 를 이해하기 위해서 제트의 남북 이동 및 대기 순 환의 변화 등에 대한 역학적인 분석이 필요할 것으 로 판단된다. 그럼에도 불구하고 본 연구에서 생 산한 미래 풍력 자원 자료는 기후변화에 대응하여 지속가능한 신재생 에너지 자원 확보를 위한 풍력 자원의 효율적인 활용 및 미래 에너지 수급 및 활 용계획에 있어서 기초 자료로 활용가치가 높을 것 으로 판단된다.

\section{사사}

본 연구는 국립기상과학원 주요사업 "고해상도 기상자원 예측시스템 개발 연구(II)"의 지원으로 수행되었습니다.

\section{참고문헌}

Baek, H.-J., Lee, J., Lee, H.-S., Hyun, Y.-K., Cho, C. H., Kwon, W.-T., Marzin, C., Gan, S.-Y., Kim, M.-J., Choi, D.-H., Lee, J., Lee, J., Boo, K.-O., Kang, H.-S., and Byun, Y.-H., 2013, Climate change in the 21 st century simulated by HadGEM2-AO under representative concentration pathways, Asia-Pacific Journal of Atmospheric Sciences, 49(5), 603-618.

Barstad, I., Sorteberg, A., and Mesquita, M. S., 2012,
Present and future offshore wind power potential in northern Europe based on downscaled global climate runs with adjusted SST and sea ice cover, Renewable Energy, 44, 398-405.

Beak, S.-G. and Jang, D.-H., 2011, Evaluation for Applicability of Cokriging for High Resolution Spatial Mapping of Temperature and Rainfall, Journal of Climate Research, 6(3), 242-253 (in Korean).

Byon, J.-Y., Kim, Y., and Choi, B.-C., 2014, Variability of future wind and solar resource over the Korean peninsula based on climate change scenario, Journal of the Korean Society for New and Renewable Energy, 10(2), 29-39 (in Korean).

Byon, J.-Y., Choi, Y.-J., and Lee, J.-W., 2011, Global Distribution of Surface Layer Wind Speed for the years 2000-2009 Based on the NCEP Reanalysis, Atmosphere, 21(4), 439-446 (in Korean).

Byon, J.-Y., Choi, Y.-J., and Seo, B.-K., 2010, Characteristics of a wind map over the Korean peninsula based on mesoscale model WRF, Atmosphere, 20(2), 195-210 (in Korean).

Daly, C., Conklin, D.R., and Unsworth, M.H., 2009, Local atmospheric decoupling in complex topography alters climate change impacts, International Journal of Climatology, 30(12), 18571864.

Daly, C., Gibson, W., Hannaway, D., and Taylor, G., 2000, Development of new climate and plant adaptation maps for China, 12th Conference on Applied Climatology.

Daly, C., Gibson, W. P., Taylor, G. H., Johnson G. L., and Pasteris, P. P., 2002, A knowledge-based approach to the statistical mapping of climate, Climate Research, 22(2), 99-113.

Daly, C., Halbleib, M., Smith, J. I., Gibson, W. P.,Doggett, M. K., Taylor, G. H., Curtis, J., and Pasteris, P. P., 2008, Physiographically sensi- 
tive mapping of climatological temperature and precipitation across the conterminous United States, International Journal of Climatology, 28(15), 2031-2064.

Daly, C., Helmer, E. H., and Maya, Q., 2003, Mapping the Climate of Puerto Rico, Vieques and Culebra, International Journal of Climatology, 23(11), 1359-1381.

Daly, C., Neilson, R. P., and Phillips, D. L., 1994, A statistical-topographic model for mapping Climatological precipitation over mountainous terrain, Journal of Applied Meteorology, 33(2), 140158.

Daly, C., Taylor, G. H., Gibson, W. P., Parzybok, T. W.,Johnson, G. L., and Pasteris, P. P., 2001, High quality spatial climate data sets for the United States and beyond, Transactions of the ASAE-American Society of Agricultural Engineers, 43(6), 1957-1962.

Doggett, M., Daly, C., Smith, J., Gibson, W., Taylor, G., Johnson, G., and Pasteris, P., 2004, High resolution 1971-2000 Mean monthly Temperature maps for the western United States, 14 th AMS Conference on Applied Climatology.

Gudmundsson, L., Bremnes, J. B., Haugen, J. E., and Engen-Skaugen, T, 2012, Technical Note: Downscaling RCM precipitation to the station scale using statistical transformations - a comparison of methods, Hydrology and Earth system sciences, 16(9), 3383-3390.

Heo, C.-U., Lee, Y. S., and Lee, E.-J., 2010, Spatial Distribution Characteristics of Wind Map over Korea Using Meteorological Resources, Atmosphere, 20(2), 63-71 (in Korean).

Hong, K.-O., Suh, M.-S., Rha, D.-K., Chang, D.-H., Kim, C., and Kim, M.-K., 2007, Estimation of High Resolution Gridded Temperature Using GIS and PRISM, Atmosphere, 17(3), 255-268 (in Korean)
Hsu, S. A., Meindl, E. A., and Gilhousen, D. B., 1994, Determining the power-law wind-profile exponent under near-neutral stability conditions at sea, Journal of Applied Meteorology, 33(6), $757-$ 765.

Hueging, H., Haas, R., Born, K., Jacob, D., and Pinto, J. G., 2013, Regional changes in wind energy potential over Europe using regional climate change model ensemble projections, Journal of Applied Meteorological and Climatology, 52(4), 903-917.

Jang, D.-H., Kim, M.-K., Lee, S.-H., Park, J., Kim, S., Lee, J., Oh, J., Choi, S., and Park, H., 2014, Advanced Research on Applied Meteorology: Meteorological Resource: A Study on Development of the Future Details Wind Energy-Weather Resource Maps, National Institute of Meteorological Research, Korea Meteorological Administration (in Korean).

Jung, M.-S., Moon, C., Cheang E.-H., Kim, T.-H., and Chang, Y.-H., 2010, A study on assume of Wind shear using Deacon equation, Proceedings of the KSES 2010 Spring Annual Conference, 270-274 (in Korean).

Kim, D.-W. and Byon, H.-R., 2008, Spatial and temporal distribution of Wind Resources over Korea, Atmosphere, 18(3), 171-182 (in Korean).

Kim, H.-G. and Kang, Y.-H., 2012, The 2010 Wind Resource Map of the Korean Peninsular, Journal of the Wind Engineering Institute of Korea, 16(4), 167-172 (in Korean).

Kim, H.-G., 2008, Preliminary Estimation of Wind Resource Potential in South Korea, SOLAR EN$E R G Y, 28(6), 1-7$ (in Korean).

Kim, J., Ghim, Y. S., and Chung, K.-Y., 2000, Analysis of Wind Data Characteristics of Automatic Weather Stations in Seoul and Inchon Areas, Asia-Pacific Journal of Atmospheric Sciences, 36(2), 153-166 (in Korean). 
Kim, J., Kim, M.-K., and Kim, Y.-H., 2013a, Improvement of Modified Korean Parameter-elevation Regressions an Independent Slopes Model based on Independent temperature lapse rate, Journal of climate research, 8(3), 203-215 (in Korean).

Kim, M.-K., Han, M.-S., Jang, D.-H., Baek, S.-G., Lee, W.-S., Kim, Y.-H., and Kim, S., 2012, Production Technique of Observation Grid Data of $1 \mathrm{~km}$ Resolution, Journal of Climate Research, 7(1), 55-68 (in Korean).

Kim, M.-K., Kim, S., Heo, J., Park, J.-S., Kwon, W.-T., and Suh, M.-S., 2016, Statistical downscaling for daily precipitation in Korea using combined PRISM, RCM, and quantile mapping: Part 1, Methodology, Asia-Pacific Journal of Atmospheric Sciences, 52(S), (accepted).

Kim, M.-K., Kim, S., and Kim, Y.-H., 2013b, High resolution climate change scenario based on Regional Climate Model and PRIDE Model in South Korea, Proceeding of the KSCC 2013 Autumn Annual Conference, 123 (in Korean).

Kim, M.-K., Lee, D.-H., and Kim, J., 2013c, Production and Validation of Daily Grid Data with $1 \mathrm{~km}$ Resolution in South Korea, Journal of Climate Research, 8(1), 13-25 (in Korean).

Kim, S.-M., Moon, C.-J., Jeong, M.-S., Park, B.-J., Lee, K.-S., and Park, J.-Y., 2011, The Development of the Wind Speed Measurement System using Deacon Equation Algorithm, Proceeding of the KSES 2011 Spring Annual Conference, 213-216 (in Korean)

Kim, S., Kim, M.-K., Park, J., and Jang, D.-H., 2015, An Analysis on the Characteristic of future Upper Wind over the South Korea Using Climate Change Scenarios, Journal of Climate Research, 10(3), 273-285 (in Korean).

Kim, Y., Lim, Y.-J., Lee, H.-K., and Choi, B.-C., 2014, Spatio-temporal variability of future wind energy over the Korean Peninsular using Climate
Change Scenarios, Journal of the Korean Geographical Society, 49(6), 833-848 (in Korean).

KMA, 2013, Advanced Research on Meteorological Resource (in Korean).

KMA, 2014, Production of Fine-Scale Climate Change Data over the Korean Peninsula Using RCP Scenarios (in Korean).

Kwon, Y. H., Kim, J. Y., and Lee. M. J., 2008, Environmental Considerations in the siting of Solar and Wind Power Plants, Korea Environment Institute (in Korean).

Lee, S., 2012, A Study on the Change of Wind Speed in South Korea: In Case of January and August, Journal of the Korean Geographical Society, 47(3), 347-358 (in Korean).

Lee, S.-H., 2009, Evaluation of wind Resources and Characteristics of its Distribution in the Korean Peninsula, Proceeding of the 49th Meeting of KO$S A E$, 39-43 (in Korean).

Lee, S.-H. and Kimura F., 2001, Comparative studies in the local circulations induced by land-use and by topography, Boundary-Layer Meteorology, 101(2), 157-182.

Lu X., MicElroy B. M., and Kiviluoma, J., 2009, Global potential for wind-generated electricity, Proceedings of the National Academy of Sciences, 106(27), 10933-10938.

NIMR(Natioanl Institute of Meteorological Research), 2010, Development of meteorological resources for green growth (in Korean).

Park, S., Lee, I.-H., Kang, H.-S., and Cho, C. H., 2011, Regional climate projection for East Asia and Korea using the HadGEM3-RA, The Fifth Korea-Japan-China Joint Conference on Meteorology, 89-89.

Park, J. and Jang, D.-H., 2015, Development and validation of MK-PRISM-Wind for wind speed interpolation, Journal of Climate Research, 10(4), 313-327 (in Korean). 
Park, J., Lim, Y. J., and Jang, D.-H., 2014, Improvement of a modified Korean parameter-elevation regressions on independent slopes model for wind speed interpolation, Journal of Climate Research, 9(3), 225-241 (in Korean).

Park, J.-C. and Kim, M.-K., 2013, Comparison of Precipitation Distributions in Precipitation Data Sets Representing $1 \mathrm{~km}$ Spatial Resolution over South Korea Produced by PRISM, IDW, and Cokriging, Journal of the Korean Association of Geographic Information Studies, 16(3), 147-163 (in Korean).

Park, J.-C., Jung, I.-W., Chang, H.-J., and Kim, M.-K., 2012, Optimization of PRISM Parameters and Digital Elevation Model Resolution for Estimating the Spatial Distribution of Precipitation in South Korea, Journal of the Korean Association of Geographic Information Studies, 15(3), 36-51 (in Korean).

Park, N.-W. and Jang, D.-H., 2008, Mapping of Temperature and Rainfall Using DEM and Multivariate Kriging, Journal of the Korean Geographical Society, 43(6), 1002-1015 (in Korean).

Peterson, E. W. and Hennessey Jr, J. P., 1978, On the use of power laws for estimates of wind power potential, Journal of Applied Meteorology, 17(3), 390-394.

Piani, C., Weedon, G. P., Best, M., Gomes, S. M., Viterbo, P., Hagemann, S., and Haerter, J. O.,
2010, Statistical bias correction of global simulated daily precipitation and temperature for the appli- cation of hydrological models, Journal of hydrology, 395(3), 199-215.

Pryor, S. C. and Schoof, J. T., 2010, Importance of the SRES in projections of climate change impacts on near-surface wind regimes, Meteorologische Zeitschrift, 19(3), 267-273

Pryor, S. C., Schoof, J. T., and Barthelmie, R. J., 2005, Empirical downscaling of wind speed probability distributions, Journal of Geophysical Research: Atmospheres, 110(D19),

Shin, S.-C., Kim, M.-K., Suh, M.-S., Rha, D.-K., Jang, D-.H., Kim, C.-S., Lee, W.-S., and Kim, Y.-H., 2008, Estimation of High Resolution Gridded Precipitation Using GIS and PRISM, Atmosphere, 18(1), 71-81 (in Korean).

Song, K., Bang, C.-H., Park, Y.-S., and Choi, Y.-J., 2012, Research and Analysis for Developing of Evaluation on the Site Selection of Wind Farm, Journal of the Wind Engineering Institute of Korea, 16(1), 3-12 (in Korean).

https://lpdaac.usgs.gov/dataset_discovery/modis/modis_ products_table

https://www.climate.go.kr:8005/index.html

책임편집: 박창용

영문교열: 조창현 